\title{
How efficient are referral hospitals in Uganda? A data envelopment analysis and tobit regression approach
}

\author{
Paschal N. Mujasi ${ }^{*}$, Eyob Z. Asbu ${ }^{2}$ and Jaume Puig-Junoy ${ }^{3}$
}

\begin{abstract}
Background: Hospitals represent a significant proportion of health expenditures in Uganda, accounting for about $26 \%$ of total health expenditure. Improving the technical efficiency of hospitals in Uganda can result in large savings which can be devoted to expand access to services and improve quality of care. This paper explores the technical efficiency of referral hospitals in Uganda during the 2012/2013 financial year.
\end{abstract}

Methods: This was a cross sectional study using secondary data. Input and output data were obtained from the Uganda Ministry of Health annual health sector performance report for the period July 1, 2012 to June 30, 2013 for the 14 public sector regional referral and 4 large private not for profit hospitals. We assumed an output-oriented model with Variable Returns to Scale to estimate the efficiency score for each hospital using Data Envelopment Analysis (DEA) with STATA13. Using a Tobit model DEA, efficiency scores were regressed against selected institutional and contextual/environmental factors to estimate their impacts on efficiency.

Results: The average variable returns to scale (Pure) technical efficiency score was $91.4 \%$ and the average scale efficiency score was $87.1 \%$ while the average constant returns to scale technical efficiency score was $79.4 \%$. Technically inefficient hospitals could have become more efficient by increasing the outpatient department visits by 45,943; and inpatient days by 31,425 without changing the total number of inputs. Alternatively, they would achieve efficiency by for example transferring the excess 216 medical staff and 454 beds to other levels of the health system without changing the total number of outputs. Tobit regression indicates that significant factors in explaining hospital efficiency are: hospital size $(p<0.01)$; bed occupancy rate $(p<0.01)$ and outpatient visits as a proportion of inpatient days $(p<0.05)$.

Conclusions: Hospitals identified at the high and low extremes of efficiency should be investigated further to determine how and why production processes are operating differently at these hospitals. As policy makers gain insight into mechanisms promoting hospital services utilization in hospitals with high efficiency they can develop context-appropriate strategies for supporting hospitals with low efficiency to improve their service and thereby better address unmet needs for hospital services in Uganda.

Keywords: Data envelopment analysis, Hospital efficiency, Technical efficiency, Tobit model, Uganda

\footnotetext{
* Correspondence: Pmujasi@yahoo.co.uk

${ }^{1}$ Department of Health Studies, Health Economist; Doctoral student,

University of South Africa, College of Human Sciences, 1 Preller Street,

Muckleneuk, Pretoria 0002, South Africa

Full list of author information is available at the end of the article
} 


\section{Background}

Besides equity and financial protection, the pursuit of efficiency is a key policy objective of policy makers in most health systems [1]. This is much more evident in Africa where the ability to adequately meet health care needs is exacerbated by extensive inefficiencies, especially within the hospital sector [2-8]. Conservative estimates indicate that globally, about US\$ 300 billion is lost annually to hospital-related inefficiency [9].

Hospitals represent a significant proportion of health expenditures. In Uganda for example, about $26 \%$ of Total Health Expenditure (THE) is through hospitals [10]. Hospital expenditures accounted for $37 \%$ of Government Current Health Expenditure (GCHE) in $2011 / 12$. Of this, $23 \%$ was spent on Regional referral hospitals, $66 \%$ in primary health care hospitals and $11 \%$ in specialty hospitals/Institutions [11]. A health system's efficiency is thus to a great extent determined by the efficiency of its hospitals. For example, a modeling exercise in Australia demonstrated that a $4 \%$ gain in the efficiency of hospitals would contribute to a $1.9 \%$ increase in the overall efficiency of the country's health system signifying the important role played by hospitals in influencing the overall health systems efficiency [12]. Thus improvement in the pure technical and scale efficiency of hospitals may result in large savings in healthcare expenditures, which could be devoted to expand access to preventive, promotive, curative and rehabilitative services and improve quality of care. This will contribute significantly to a country's endeavors towards achieving universal health coverage in line with the Sustainable Development Goals.

\section{Study context}

Located in East Africa, with an estimated population of $34.856 \mathrm{M}$ in 2014 [13], Uganda is a low income country served by a healthcare delivery system that comprises of the public sector, private sector and the non-governmental organizations (NGO)/private not profit sector. As of 2010, the health care delivery system comprised of 129 hospitals, 177 Health Centre IVs, 1082 health center IIIs and 3006 Health Centre IIs [14]. At the apex of the healthcare delivery system are national referral hospitals below which are regional referral hospitals to which district hospitals refer. There is a district health care delivery system below the district hospitals comprising health center IVs, IIIs and health center IIs, and village health teams. The district hospitals act as referral centers for the district health care delivery system. The regional referral hospitals act as referral centers for several districts within their catchment area [15].

The Uganda National Health Policy indicates that efficiency is currently not well addressed in the way resources are mobilized, allocated and used [16]. Thus, one of the Uganda Ministry of Health objectives in the Health sector strategy and investment plan (HSSIP 2010/11-2014/15) is to improve the efficiency and effectiveness of health services [14]). For this to be achieved, information on the current level of efficiency in delivery of the various health services and the drivers of inefficiency will be required.

The Uganda Ministry of Health $(\mathrm{MOH})$ routinely analyses and reports on efficiency of regional referral and other hospitals in its annual health sector performance reports. However, the analysis explores efficiency in a general sense using ratio indicators, mainly, the standard unit of output (SOUs) per health worker. The analysis does not take into account other factors of production (e.g. Beds, finances etc.) used by the hospitals in the production of the outputs. Additionally, the report does not include any deep analysis of the factors affecting hospital efficiency and the required changes to improve efficiency. Such information would be useful to the $\mathrm{MOH}$ in taking the required actions to improve efficiency, which is one of the health policy objectives. Additionally, there are no recently published facility efficiency studies in Uganda, with the available studies having been published in 2010 and 2008 [17, 18] using 1999-2003 data. These studies can be considered outdated given that a lot has happened since then in terms of the country's socioeconomic and health development.

This study tries to address these gaps. The study demonstrates how a study of hospital efficiency using Data Envelopment Analysis (DEA) and routinely reported data can inform decision-making.

\section{Conceptual framework}

\section{Hospitals as production units}

Hospitals use multiple health system inputs to produce multiple health service outputs through a production process. Inputs (labor and capital) combine via medical and surgical care to produce outputs. While the ultimate output of healthcare is the marginal change in health status, this is difficult to measure in most data sets, and so intermediate outputs - episodes of care (e.g. number of operations and outpatient visits) - usually become the primary study outputs. This production process does not occur in a vacuum; it can be influenced by a number of environmental factors both internal and external to the hospital which may influence how efficiently the production process occurs [19]. Often these factors are considered to be uncontrollable by the hospital managers. The factors are theorized either to affect the production process itself or to influence directly the efficiency of the process [20].

Figure 1 depicts the relationship between health system inputs, the production process, and the outputs/ results. This forms the framework for our study. 

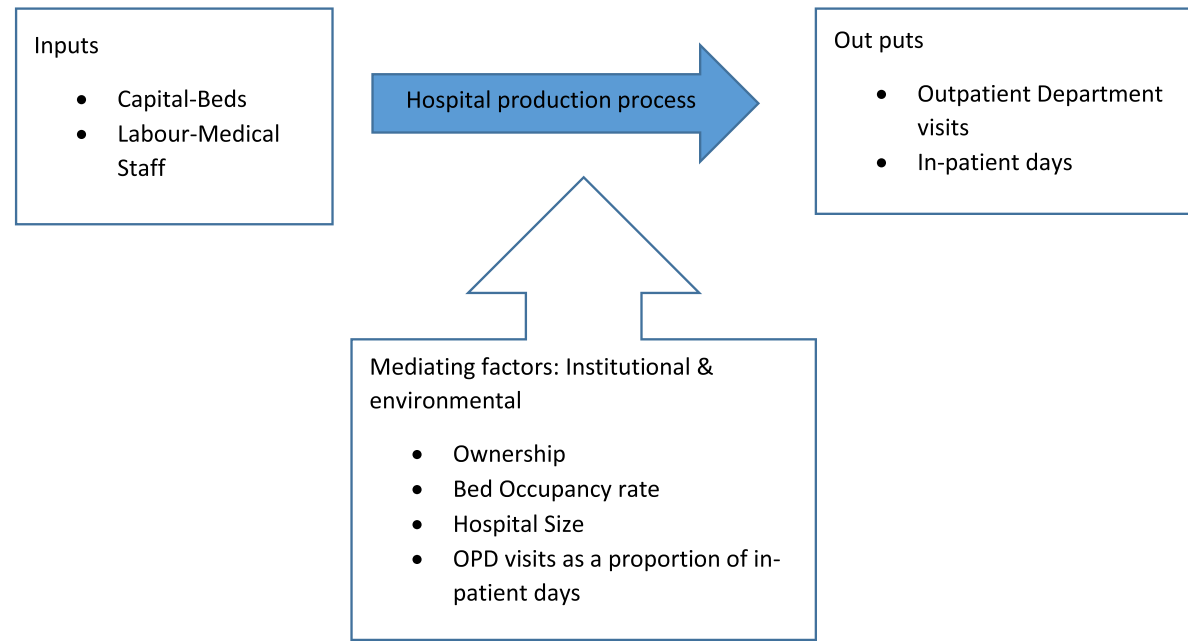

Fig. 1 Uganda referral hospital inputs, process, out puts and influencing factors

\section{Efficiency concepts}

Skaggs and Carlson [21] define economic efficiency as obtaining the maximum benefit from a given cost or minimizing the cost of a given benefit. Economic efficiency comprises both technical efficiency (producing without waste) and allocative efficiency (allocating resources to their most high value uses).

Technical efficiency is achieved when a health decision making unit (DMU) produces a given level of health service outputs with the least health system inputs, e.g. health workforce, pharmaceutical and nonpharmaceutical supplies and capital inputs (buildings, beds, equipment, vehicles etc.).

The technical efficiency of a health DMU is decomposed into pure technical efficiency and scale efficiency. Pure technical efficiency denotes technical efficiency that cannot be attributed to deviations from optimal scale (scale efficiency). Scale efficiency on the other hand is a measure of the extent to which a health decision making unit deviates from optimal scale (defined as the region in which there are constant returns to scale in the relationship between outputs and inputs) [22, 23].

Salvatore [24] defines returns to scale as the extent to which health system output changes as a result of a change in the quantity of all health system inputs used in production. A constant return to scale is achieved when the quantity of health service outputs increase in the same proportion as the increase in the quantity of all inputs. An increasing return to scale is achieved if output increases by a greater proportion than the increase in inputs and a decreasing return to scale is achieved where output increases by a smaller proportion than the increase in inputs.

In the context of health, allocative efficiency describes the use of health system inputs by a health facility or decision-making unit (DMU) in the proportion that minimizes the cost of production, given input prices [22-24]. On the other hand, technical efficiency describes the production by a health DMU of the optimal/ maximum quantity of outputs from the available health system inputs [22-24].

Efficiency is never absolute; instead it is always assessed relative to some criterion. Cooper et al. [25] explain that a DMU is to be rated as fully (100\%) efficient on the basis of available evidence if and only if the performances of other DMUs does not show that some of its inputs or outputs can be improved without worsening some of its other inputs or outputs. Efficiency scores are bounded by zero (totally inefficient) and one (totally relatively efficient).

\section{Data envelopment analysis}

DEA is a non-parametric, data driven approach that uses linear programming techniques to compute the efficiency scores for each DMU in a data set. DMUs that are technically efficient have a score of 1 or $100 \%$, whereas inefficient ones have efficiency scores of less than 1 (i.e. less than $100 \%$ ).

In DEA the efficiency of a DMU (referral hospitals in this case) is measured relative to a group's observed best practice. This implies that the benchmark against which to compare the efficiency of a particular referral hospital is determined by the group of referral hospitals in the study and not a value fixed by hospitals outside of the group.

DEA easily accommodates multiple inputs and outputs without the requirement for a common denominator of measurement. This makes it particularly suitable for analyzing the efficiency of hospitals as they use multiple inputs to produce many outputs. Furthermore, it 
provides specific input and output targets that would make an inefficient hospital relatively efficient. It also identifies efficient peers for those hospitals that are not efficient. This helps the inefficient hospitals to emulate the functional organization of their peers so as to improve their efficiency.

However, like many other empirical methods, DEA has its limitations. First, it produces results that are sensitive to measurement error. For example, if one hospital's inputs are understated or its outputs overstated, it can become an outlier and significantly reduce the efficiency of other hospitals. Second, DEA measures efficiency relative to the best practice within hospitals in the particular sample.

A growing number of African countries have undertaken health facility efficiency studies using data envelopment analysis (DEA) to guide the development of interventions to reduce waste of scarce health system resources. Since 2000 studies have been undertaken in a number of countries, including Angola [2], Namibia [3], Botswana [4], Zambia [5] Kenya [6, 26], Benin [27], Burkina Faso [28], Ethiopia [29], Ghana [30-32], Nigeria [33], Seychelles [34], Sierra Leone [35, 36], South Africa [7, 37], Uganda [18] and Eritrea [38]. These studies demonstrate that DEA is an important tool for policy advice.

\section{Research questions and objectives}

We address three research questions: What was the technical efficiency of regional referral and large private not for profit (PNFP) hospitals in Uganda in FY 2012/ 2013? What is the scope for increase in outputs of the same quality by the regional referral hospitals without increasing the amount of resources used? How do institutional and contextual/environmental variables affect efficiency of regional referral hospitals in Uganda?

The specific objectives of our study are: (a) to estimate the technical and scale efficiency of regional referral hospitals in Uganda in FY 2012/2013 (b) to estimate the magnitudes of output increases of the same quality that would have been required to make relatively inefficient hospitals more efficient; and (c) to determine the impact of institutional and/or contextual/environmental variables on hospital inefficiencies. We use two-stage DEA: (i) to estimate efficiency of the regional referral hospitals; and (ii) explain the inefficiencies using Tobit regression.

\section{Methods}

\section{Study design}

This was a cross sectional study using secondary data.

\section{Study population}

In Uganda, regional referral hospitals offer specialist clinical services such as psychiatry, Ear, Nose and Throat (ENT), ophthalmology, higher level surgical and medical services, and ancillary services (laboratory, medical imaging and pathology). They are also involved in teaching and research. This is in addition to the following services provided by general hospitals: preventive, promotive, curative, maternity, in-patient health services, surgery, blood transfusion, laboratory and medical imaging services [14].

For the financial year 2012/13, there were a total of 14 public sector regional referral hospitals operational in Uganda. Additionally, there were 4 large PNFP hospitals with the same range of services as public sector regional referral hospitals [39]. Thus, our study population comprised of 18 hospitals.

A data base of inputs and outputs for all the 14 public sector regional referral and the 4 PNFP hospitals was compiled from various sections of the 2012/2013 MOH annual health sector performance report [39]. Our final study sample comprised of 17 hospitals. One PNFP hospital was excluded from the study for lack of data.

\section{Data and variables}

Our study uses Uganda hospital data for the 2012/2013 Financial year (July 1, 2012 to June 30, 2013) as reported by the $\mathrm{MOH}$ in the annual health sector performance report (AHSPR) to explore the technical efficiency of regional referral and large private not for profit (PNFP) hospitals during that period.

\section{Input and output variables}

Data was assembled for 3 different inputs (medical staff, hospital beds, budget) and 5 outputs (OPD visits, inpatient days, deliveries, major operations and immunizations). Based on completeness of available data, final selection was limited to 2 input and 2 outputs. The inputs included total number of medical staff and hospital beds. The outputs included outpatient department (OPD) visits and in-patient days. We presume these capture most of the hospital activities. For example surgeries are also subsumed in inpatient and outpatient care (if day case surgeries).

The input and output variables are described in Table 1.

The choice of the above-mentioned inputs and outputs was guided by three considerations, namely: past studies undertaken of hospitals in Africa, which also employed similar inputs and outputs [2-8;28-38;]; the availability of relevant data in the ministry of health annual health sector performance report for FY 2012/13 [39]; and the availability of data that is routinely compiled by hospitals in order to demonstrate ways in which the Uganda $\mathrm{MOH}$ can get added informational value from such data without investing extra resources. The inputs and outputs data were used as reported in the 
Table 1 Definition of study variables

\begin{tabular}{|c|c|c|c|}
\hline Variables & Definition & Measurement & Data Source \\
\hline \multicolumn{4}{|c|}{ Input variables } \\
\hline BEDS & Beds & Total number of hospital beds during the financial year & $\begin{array}{l}\text { Annual Health Sector Performance Report } \\
\text { 2012/2013 }\end{array}$ \\
\hline STAFF & Medical Staff & $\begin{array}{l}\text { Total number of doctors, nurses, Clinical officers, } \\
\text { Laboratory technicians and anesthetic officers. }\end{array}$ & $\begin{array}{l}\text { Annual Health Sector Performance Report } \\
\text { 2012/2013 }\end{array}$ \\
\hline \multicolumn{4}{|c|}{ Output variables } \\
\hline INPATDAYS & In Patient days & Total number of inpatient days for the Financial year & $\begin{array}{l}\text { Annual Health Sector Performance Report } \\
\text { 2012/2013 }\end{array}$ \\
\hline OPD & Outpatient visits & $\begin{array}{l}\text { Total number of outpatient visits during the Financial } \\
\text { year }\end{array}$ & $\begin{array}{l}\text { Annual Health Sector Performance Report } \\
\text { 2012/2013 }\end{array}$ \\
\hline \multicolumn{4}{|c|}{ Explanatory variables } \\
\hline BOR & Bed Occupancy Rate & $\begin{array}{l}\text { Proportion of beds which are occupied over a specified } \\
\text { period of time }\end{array}$ & $\begin{array}{l}\text { Annual Health Sector performance report } \\
2012 / 2013\end{array}$ \\
\hline OPDIPD & $\begin{array}{l}\text { Outpatient visits as a proportion } \\
\text { of inpatient days; }\end{array}$ & $\begin{array}{l}\text { Total Outpatient department visits divided by the total } \\
\text { inpatient days }\end{array}$ & $\begin{array}{l}\text { Annual Health Sector performance report } \\
\text { 2012/2013 (calculated) }\end{array}$ \\
\hline ALOS & Average Length of Stay & $\begin{array}{l}\text { Average number of days that patients spend in } \\
\text { hospital. Measured by dividing the total number of } \\
\text { days stayed by all inpatients during a year by the } \\
\text { number of admissions }\end{array}$ & $\begin{array}{l}\text { Annual Health Sector performance report } \\
2012 / 2013\end{array}$ \\
\hline SIZE & Hospital Size & Number of beds in the hospital. 1 if $>190$ and 0 if $<190$ & $\begin{array}{l}\text { Annual Health Sector performance report } \\
2012 / 2013\end{array}$ \\
\hline OWN & Ownership & $\begin{array}{l}\text { Governing authority of hospital. } 1 \text { if Government/ } \\
\text { private hospital owned; } 0 \text { if NGO/PNFP }\end{array}$ & $\begin{array}{l}\text { Annual Health Sector performance report } \\
2012 / 2013\end{array}$ \\
\hline TEACH & Teaching status & $\begin{array}{l}\text { Whether a hospital is attached to a university or not for } \\
\text { the purpose of training medical students (doctors \& } \\
\text { Pharmacists) }\end{array}$ & Individual hospital website \\
\hline DIST & Distance & $\begin{array}{l}\text { Distance of the teaching hospital from the capital city. } \\
1 \text { if and } 0 \text { if }\end{array}$ & Individual hospital website \\
\hline POP & Population size & $\begin{array}{l}\text { Total population of districts in the hospital's catchment } \\
\text { area.: } 1 \text { if and } 0 \text { if }\end{array}$ & $\begin{array}{l}\text { Uganda National Population and Housing } \\
\text { Census } 2014 \text { (calculated) }\end{array}$ \\
\hline
\end{tabular}

ministry's annual health sector performance report without any processing or manipulation.

\section{Explanatory variables}

The literature indicates that some of the factors that impact health facility efficiency include, catchment population, distance, location (urban/rural), ownership (profit/not-for-profit), teaching status, payment source (out-of-pocket/health insurance), occupancy rate, average length of stay, outpatient visits as a proportion of inpatient days, and quality [7, 40, 41]. These can be considered as explanatory variables for hospital efficiency.

In our study, we selected the explanatory variables based on availability of data. They are also described in Table 1.

\section{Data management and analysis methods}

The data collected on inputs, outputs and explanatory variables were entered into a computer using Excel software. The excel data were then exported into STATA 13. Data analysis was conducted in two stages. STATA 13 was used for data analysis in both stages.
First stage analysis-data envelopment analysis (DEA)

We used DEA to calculate the efficiency scores for each of the hospitals in the sample. Using STATA, we run an output-oriented model with Variable Returns to Scale (VRS) to estimate the individual hospital efficiency scores. The VRS model estimated the pure technical efficiency and scale efficiency for each of the sample hospitals. From the VRS model, we analyzed whether a hospital's production indicated increasing return to scale, constant return to scale, or decreasing return to scale.

The VRS model was adopted under the assumption that in practice there are variable returns to scale and not all hospitals are operating at an optimal scale. Also, given the existence of unmet need and low quality of care, we wanted to investigate the potential efficiency savings that can be used to expand care and/or improve quality.

According to Coelli [42], where DMUs are given a fixed quantity of resources (inputs) and asked to produce as much output as possible, an output orientation is more appropriate. In the Ugandan context hospitals have a more or less fixed quantity of inputs and 
managers are expected to produce as much output as possible. For example, the staffing capacity of each hospital is determined centrally by the $\mathrm{MOH}$ or hospital managing authority, and thus individual hospital managers do not have any control over the size of the health workforce. Even when inputs such as beds and staff are underutilized, it is not within the managers' power to dispose of them.

\section{Model specification}

Assuming that there are $\mathrm{j}$ referral hospitals, each with $\mathrm{n}$ hospital inputs and $\mathrm{m}$ hospital outputs, the relative efficiency score of a given hospital $\left(\theta_{0}\right)$ is obtained by solving the following output-orientated CCR DEA linear programming model:

$$
\text { Maximise } \begin{aligned}
\theta & =U_{1} Y_{1_{o}}+U_{2} Y_{2_{o}}+\cdots \\
& +U_{r} Y_{r_{o}}\left(=\sum_{r=1}^{s} U_{r} Y_{r_{o}}\right)
\end{aligned}
$$

Subject to the constraints that:

$$
\begin{aligned}
& v_{1} x_{1_{o}}+v_{2} x_{2_{o}}+\cdots+v_{m} x_{m_{o}}=\sum_{i=1}^{m} v_{i} x_{i_{o}}=1 \\
& x_{1 j}+v_{2} x_{2 j}+\cdots+v_{m} x_{m j}
\end{aligned}
$$

Where:

$\theta_{0}=$ the efficiency score of hospital 0 ;

$\mathrm{X}_{\mathrm{nj}}=$ the amount of health system input $\mathrm{n}$ utilized by the $\mathrm{j}^{\text {th }}$ hospital;

$\mathrm{Y}_{\mathrm{mj}}=$ the amount of health system output $\mathrm{m}$ produced by the $\mathrm{j}^{\text {th }}$ hospital;

$\mathrm{u}_{\mathrm{m}}=$ weight given to health system output $\mathrm{m}$;

$\mathrm{v}_{\mathrm{n}}=$ weight given to output $\mathrm{n}$

One of the main drawbacks of DEA is that the resulting efficiency scores are sensitive to the presence of DMUs that perform extremely well (outliers), either due to outstanding practice or errors in the data. In either case, the results for the remaining DMUs become shifted towards lower efficiency levels, the efficiency frequency distribution becomes highly asymmetric, and the overall efficiency scale becomes nonlinear. Thus, we used jackknife analysis to test for the robustness of the DEA technical efficiency measures and assess if there were extreme outliers affecting the frontier and efficiency scores. In conducting the jackknife analysis, we dropped each efficient hospital one at a time from the analysis and efficiency scores reestimated. We tested the similarity of the efficiency rankings between the model with all the hospitals included and those based on dropping each efficient hospital one at a time using the Spearman rank correlation coefficient. The efficiency scores obtained were robust as indicated by Spearman rank correlation coefficient, which was very close to one.

\section{Second stage- econometric analysis (Tobit Regression)}

In the second stage, the DEA efficiency scores computed in the previous section were regressed against some institutional factors which are at the discretion of the hospital management and selected contextual/environmental (non-discretionary) factors that are beyond their control to estimate their impacts on efficiency. These factors are already described in Table 1.

Thus, using the VRS technical efficiency scores as a dependent variable and given that the scores are rightcensored (i.e. upper limit of $100 \%$ ), a Tobit regression model was used to estimate the adjusted efficiency scores for each hospital.

The Tobit obtains estimates of the linear Tobit model, where the dependent variable is either zero or positive. The method used was maximum likelihood under the assumption of homoscedastic normal disturbances.

The following Tobit regression Model was used:

$$
\text { Tobit }\left(Y_{i}\right)=a_{0}+a_{1} x_{j_{1}}+a_{2} x_{j_{2}}+a_{3} x_{j_{3}}+\cdots+\varepsilon_{j}
$$

Where:

yj is the variable return to scale efficiency score for the jth hospital,

$\mathrm{xj}$ are the explanatory variables,

$\varepsilon j$ are the disturbance term assumed to be normally distributed with mean $\mu$ and standard deviation $\sigma$

$\alpha$ are the Tobit coefficients which indicate how a one unit change in an independent variable $x_{i}$ alters the latent dependent variable $\mathrm{y}_{\mathrm{i}}$. Sometimes the values of the tobit coefficients cannot be interpreted but their signs are helpful for interpreting the results of study

Following Asbu [43], the VRS DEA technical efficiency scores were transformed into inefficiency scores, leftcensored at zero using the formula:

$$
\text { Inefficiency Score }=\left(\frac{1}{D E A T E \text { score }}\right)-1
$$

The initially estimated general model contained all the identified explanatory variables and was:

$$
\begin{aligned}
\text { Ineff }=\alpha & +\beta_{1} \text { OPDIPD }+\beta_{2} \text { BOR }+\beta_{3} \text { SIZE } \\
& +\beta_{4} \text { OWN }+\beta_{5} \text { ALOS }+\beta_{6} \text { TEACH } \\
& +\beta_{7} \text { DIST }+\beta_{8} \text { POP }+\varepsilon_{i}
\end{aligned}
$$

Where $\beta$ is the vector of unknown parameters or coefficients; and $\varepsilon$ i is the stochastic/random error term. We estimated the Tobit regression using Stata 13 for Windows. By estimating the empirical model, we wished to test two hypotheses: First, in order to test the overall significance of the model, we state the joint null hypothesis as $\mathrm{H0}$ : $\beta 1=\beta 2=\beta 3=\beta 4=\beta 5=0$ and the alternative 
hypothesis $\mathrm{HA}: \beta 1=\beta 2=\beta 3=\beta 4=\beta 5=\beta 6=\beta 7=\beta 8 \neq 0$. The joint null hypothesis is tested using the likelihood ratio test (LL).

Second, we wished to test the hypothesis that $\beta \mathrm{n}$ is not significantly different from zero in either direction. Thus, the null ( $\mathrm{HO})$ and alternative hypotheses $(\mathrm{HA})$ are: $\mathrm{HO}: \beta \mathrm{n}=0$; and HA : $\beta \mathrm{n} \neq 0$ The individual null hypotheses are tested using the $\mathrm{t}$-distribution test.

However, the objective was to estimate a parsimonious tobit model that would help explain the observed inefficiencies. Such a model would be significant based on the Chi square. Thus, through an iterative process, we run several models containing various combinations of the explanatory variables.

The finally selected empirical model based on the Chi Square was:

$$
\begin{aligned}
\text { Ineff } & =\alpha+\beta_{1} \text { OPDIPD }+\beta_{2} \text { BOR }+\beta_{3} \text { SIZE } \\
& +\beta_{4} \text { OWN }+\varepsilon_{i}
\end{aligned}
$$

Based on past two-stage hospital efficiency studies [10], we would expect a negative relationship between the Ineff and OPDIPD, and thus, $\beta 1$ should a priori assume a negative sign. We would expect a negative relationship between the Ineff and OPDIPD, and thus, $\beta 1$ should a priori assume a negative sign. Tobit coefficients indicate how a one unit change in an independent variable $x_{i}$ alters the latent dependent variable $y^{*}$.

\section{Ethical clearance}

This study is entirely an analysis of data from published secondary sources. Since human subjects were not involved, it did not require ethical clearance.

\section{Results}

\section{Descriptive analysis of inputs and output variables}

Table 2 presents the descriptive statistics (sum, minimum, maximum, mean and standard deviation) for inputs and outputs of referral hospitals in our sample (public sector regional referral and large Private not for Profit) during the FY 2012/13 (July 1, 2012 to June 1,

Table 2 Descriptive statistics of the input, output and explanatory

\begin{tabular}{|c|c|c|c|c|}
\hline & Mean & $\begin{array}{l}\text { Standard } \\
\text { deviation }\end{array}$ & Minimum & Maximum \\
\hline \multicolumn{5}{|l|}{ Inputs } \\
\hline Number of Clinical staff & 202 & 88 & 97 & 453 \\
\hline Number of beds & 287 & 117 & 100 & 482 \\
\hline \multicolumn{5}{|l|}{ Outputs } \\
\hline $\begin{array}{l}\text { Number of outpatient } \\
\text { department visits }\end{array}$ & 143,654 & 51,339 & 35,390 & 209,032 \\
\hline Patient days & 87,344 & 41,052 & 24,382 & 176,671 \\
\hline
\end{tabular}
variables for Regional Referral and large PNFP hospitals $(n=17)$
2013). During the study period, the 17 hospitals received 2,442,117 outpatient department visits and provided $1,484,853$ inpatient days of care. These outputs were produced using a total of 3433 Medical staff and 4874 hospital beds.

There was wide variation in both output and inputs across the different hospitals. The outpatient department visits varied from a minimum of 35,390 to a maximum of 209,032 . The inpatient days of care provided varied from a minimum of 24,382 days to 176,671 days. In terms of inputs there was considerable variation as well: the number of medical staff varied between 97 and 453; and hospital beds varied between 100 and 482 .

\section{Descriptive analysis of explanatory variables}

Table 3, shows the distribution of explanatory variables in the study sample.

The majority of hospitals in the sample ( $82 \%)$ were public hospitals owned by the government. Two hospitals (12\%) were teaching hospitals. Nine hospitals (53\%) had a catchment population greater than 1.5 million. Three hospitals (18\%) were located within 200 kilometers from the capital city.

For purposes of this study, hospitals with more than 190 hospital beds (lower quantile) were categorized as big hospitals. Based on this categorization, $24 \%$ of the hospitals in our study sample could be considered small hospitals with the remaining $76 \%$ categorized as large hospitals.

The bed occupancy rate varied from 40.8 to $100 \%$ with a mean of $81.4 \%$ and standard deviation $19.9 \%$. The proportion of outpatient department visits as a proportion of inpatient days varied from 0.44 to 5.30 with a mean of 2 and standard deviation of 1.27 . The average length of stay was 4.6 days with a standard deviation of 1.2 days. The average length of stay ranged from 3 to 7 days.

\section{Technical efficiency}

Table 4 shows the individual hospital DEA scores for constant returns to scale technical efficiency, variable returns to scale technical efficiency (pure technical efficiency), scale efficiency, and returns to scale. The table also shows the efficiency reference set for each hospital, which refers to the group of hospitals against which DEA located the relatively inefficient hospitals and the magnitudes of inefficiency.

Overall, 3 hospitals (18\%) were operating under constant returns to scale, implying that they were efficient (both pure technical and scale efficiency). A percentage change in inputs is accompanied by the same percentage change in outputs.

Ten hospitals (59\%) were operating under diminishing returns to scale, implying that their health service 
Table 3 Distribution of explanatory variables

\begin{tabular}{|c|c|c|c|c|}
\hline & Mean & Standard deviation & Minimum & Maximum \\
\hline \multicolumn{5}{|l|}{ Continuous variables } \\
\hline Bed Occupancy Rate (BOR) & $81.4 \%$ & $19.9 \%$ & $40.8 \%$ & $100 \%$ \\
\hline Outpatient department visits as a proportion of In-patient stays (OPDIPD) & 2 & 1.27 & 0.48 & 5.30 \\
\hline \multirow[t]{2}{*}{ Average Length of Stay (ALOS)-days } & 4.6 & 1.2 & 3 & 7 \\
\hline & & Description & Number & Percentage \\
\hline \multicolumn{5}{|l|}{ Categorical Variables } \\
\hline \multirow{2}{*}{$\begin{array}{l}\text { Catchment Population (POP)- } 1 \text { if catchment population less than } \\
1.5 \text { million and } 0 \text { if greater than } 1.5 \text { million }\end{array}$} & & 0 & 8 & $47 \%$ \\
\hline & & 1 & 9 & $53 \%$ \\
\hline \multirow{2}{*}{$\begin{array}{l}\text { Distance from city (DIST) } 1 \text { if hospital located greater than } 200 \mathrm{Km} \\
\text { Kilometres from capital city and } 0 \text { if located less than } 200 \mathrm{~km}\end{array}$} & & 1 & 14 & $82 \%$ \\
\hline & & 0 & 3 & $18 \%$ \\
\hline \multirow[t]{2}{*}{ Teaching Status (TEACH) 1 if Teaching Hospital and 0 if not } & & 0 & 15 & $88 \%$ \\
\hline & & 1 & 2 & $12 \%$ \\
\hline \multirow[t]{2}{*}{ Hospital Ownership (OWN) -1 if government/MOH and 0 if NGO/PNFP } & & 0 & 3 & $18 \%$ \\
\hline & & 1 & 14 & $82 \%$ \\
\hline \multirow[t]{2}{*}{ Hospital Size (SIZE)-1 if $>190$ hospital beds and 0 if $<190$ hospital beds } & & 0 & 4 & $24 \%$ \\
\hline & & 1 & 13 & $76 \%$ \\
\hline
\end{tabular}

Table 4 Output oriented DEA efficiency scores for Table 2 descriptive statistics of the input and outputs for Regional Referral and large PNFP hospitals $(n=17)$

\begin{tabular}{|c|c|c|c|c|c|}
\hline \multirow[t]{2}{*}{ Hospital } & \multicolumn{3}{|c|}{ Efficiency scores } & \multirow[t]{2}{*}{ Returns to scale } & \multirow[t]{2}{*}{ Reference set (lambda weights) } \\
\hline & CRS_TE & VRS_TE & Scale & & \\
\hline Gulu & 1 & 1 & 1 & Constant returns to scale & \\
\hline Hoima & 1 & 1 & 1 & Constant returns to scale & \\
\hline Mbale & 0.940133 & 1 & 0.940133 & Diminishing returns to scale & \\
\hline Moroto & 1 & 1 & 1 & Constant returns to scale & \\
\hline Masaka & 0.8954 & 1 & 0.8954 & Diminishing returns to scale & \\
\hline Lira & 0.900694 & 1 & 0.900694 & Diminishing returns to scale & \\
\hline Nsambya & 0.431078 & 1 & 0.431078 & Diminishing returns to scale & \\
\hline St. Mary's Lacor & 0.692294 & 1 & 0.692294 & Diminishing returns to scale & \\
\hline Mbarara & 0.861657 & 0.976592 & 0.88231 & Diminishing returns to scale & Masaka (0.406617), Mbale (0.309851), Gulu (0.097515), Hoima (0.162609) \\
\hline Soroti & 0.850387 & 0.941373 & 0.903348 & Diminishing returns to scale & Gulu (0.260962) Hoima (0.250726) Mbale (0.323689); Moroto (0.105996) \\
\hline Fort Portal & 0.76477 & 0.921675 & 0.829762 & Diminishing returns to scale & Hoima (0.037365) Masaka (0.884309) \\
\hline Jinja & 0.70878 & 0.86767 & 0.816877 & Diminishing returns to scale & Masaka (0.640645) St. Mary's Lacor (0.114007); Mbale (0.113018) \\
\hline Arua & 0.75922 & 0.855481 & 0.887478 & Diminishing returns to scale & Gulu (0.055922) ;Mbale (0.008273), Masaka (0.791286) \\
\hline Mubende & 0.847976 & 0.850297 & 0.99727 & Increasing returns to scale & Gulu (0.064533), Hoima (0.318159); Mbale (0.005493); Moroto (0.462112) \\
\hline Kabale & 0.81319 & 0.843276 & 0.964323 & Increasing returns to scale & Masaka (0.125589) Hoima (0.702674); Lira (0.015013) \\
\hline Rubaga & 0.524107 & 0.762422 & 0.687424 & Increasing returns to scale & Gulu (0.126505) Nsambya (0.19374);Masaka (0.442177) \\
\hline Naguru & 0.509215 & 0.523887 & 0.971994 & Increasing returns to scale & Gulu (0.408324), Moroto (0.077042) \\
\hline Min & 0.431078 & 0.523887 & 0.431078 & & \\
\hline Max & 1 & 1 & 1 & & \\
\hline Mean & 0.794053 & 0.914275 & 0.870611 & & \\
\hline SD & 0.174409 & 0.125919 & 0.149222 & & \\
\hline
\end{tabular}


outputs would increase by a smaller proportion compared to any increase in health service inputs. These hospitals would have to reduce their size to achieve optimal scale.

Four hospitals $(24 \%)$ were operating under increasing returns to scale implying that their health service outputs would increase by a greater proportion compared to any increase in health services inputs. These hospitals would need to increase their size to achieve optimal scale, i.e. the scale at which there are constant returns to scale in the relationship between inputs and outputs.

Figure 2 shows the distribution of pure technical, constant returns to scale, and scale efficiency scores among the hospitals in the sample.

The figure demonstrates that constant return to scale inefficiency was a widespread problem in our sample, with only three hospitals (18 \%) being CRS technically efficient. The mean constant return to scale technical efficiency was $79.4 \%$, with a standard deviation of $17.4 \%$. The constant return to scale technical efficiency score varied from a minimum of $43.1 \%$ to a maximum of $100 \%$.

Scale inefficiency was equally a widespread problem in our sample, with only three hospitals (18\%) being Scale technically efficient. The average scale efficiency score was $87.1 \%$ (standard deviation $=14.9 \%$ ), meaning that on average, the scale inefficient hospitals could theoretically reduce their size by $12.9 \%$ without affecting their current output levels.

Pure technical inefficiency was less of a problem, with slightly less than half (Eight hospitals-47 \%) of the hospitals being VRS technically efficient. The overall sample average pure technical efficiency score was 91.4 \% (standard deviation $=12.6 \%$ ), meaning that inefficient hospitals could, on average, produce $8.6 \%$ more health service outputs using their current inputs. The lowest pure technical efficiency score was $52.4 \%$.

\section{Pearson correlation analysis}

Before conducting the tobit regression analysis, we analyzed the correlation between the traditional partial indicators of efficiency that were included in the explanatory variables list in Table 1 with different efficiency measures obtained using DEA. The indicators considered were Bed occupancy Rate (BOR), Average Length of Stay (ALOS) and proportion of outpatient department visits as a proportion of inpatient days (OPDPID). Ideally, these indicators should not be considered as explaining factors of efficiency scores especially if they are highly correlated to the efficiency scores, because they only partially measure the relation between some inputs and outputs.

The average length of stay (ALOS) and the proportion of outpatient department visits as a proportion of inpatient days were not significantly correlated with any of the efficiency scores. The bed occupancy rate however was positively and highly correlated with the constant returns to scale and scale efficiency scores but not the technical efficiency score. The higher the bed occupancy rate, the higher the constant returns to scale and Scale Efficiency. If there is no reason to consider capacity excess as valued traditional output, the occupancy rate may be related to hospital efficiency.

\section{Econometric analysis of the determinants of inefficiency}

The selected Tobit model for explaining the observed hospital inefficiencies was earlier presented. The model contained the following variables: hospital size (SIZE), hospital ownership (OWN), proportion of outpatient department visits as a proportion of inpatient days (OPDID) and bed occupancy rate (BOR).

Table 5 presents the Tobit regression model results.

The joint null hypothesis that $\mathrm{HO}: \beta 1=\beta 2=\beta 3=\beta 4$ $=\beta 4=0$ is rejected at the $1 \%$ percent level of significance (Prob $X^{2}<0.01$ ). Therefore, we can conclude that the regression coefficients for the explanatory variables

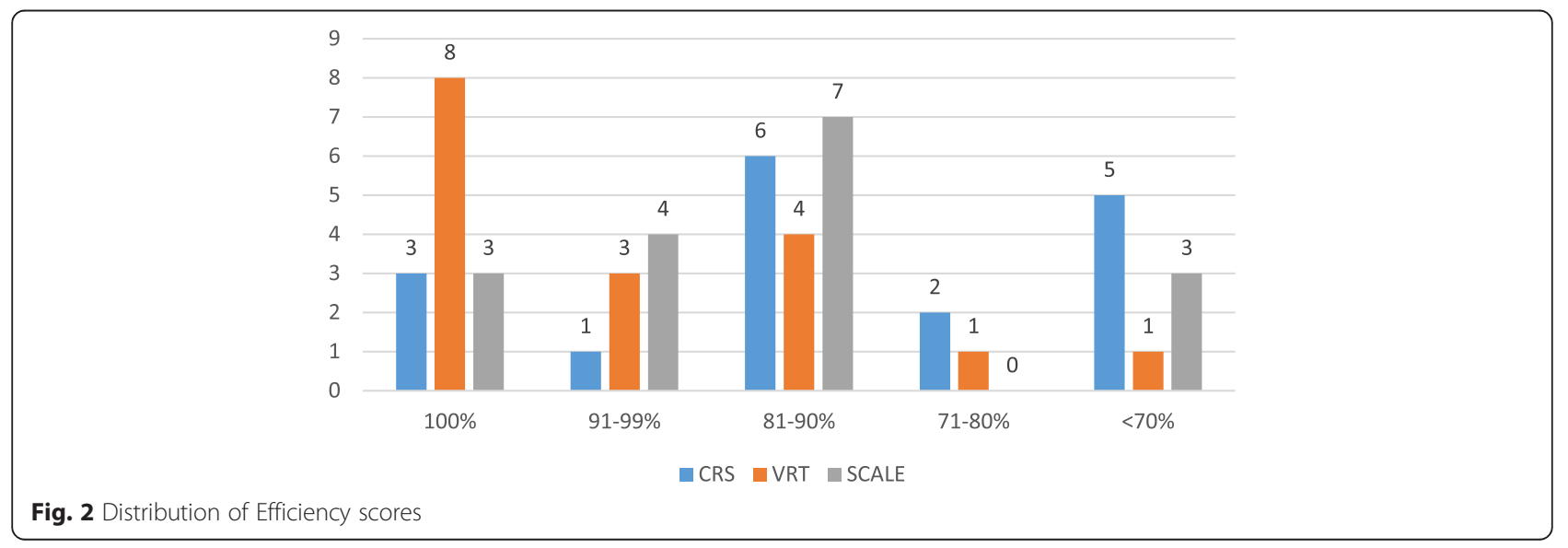


Table 5 Results of tobit model

\begin{tabular}{llll}
\hline Variable & Coefficient & $\mathrm{t}$ & $P>|\mathrm{t}|$ \\
\hline SIZE & -0.3173112 & -3.50 & $0.004^{* *}$ \\
OWN & 0.919808 & 0.79 & 0.446 \\
OPDID & -0.0950934 & -2.47 & $0.028^{*}$ \\
BOR & -1.097405 & 4.24 & $0.001^{* *}$ \\
Cons & 1.376723 & 4.67 & 0.000 \\
Sigma & 0.1448706 & & \\
& ${ }^{* *} p<0.01 ;$ & ${ }^{*} p<0.05$ & \\
Observations Summary & & 17 \\
Number of observations & & 15.42 \\
LR $x^{2}$ & & 0.0039 \\
Prob $>X^{2}$ & & & 6.7537247 \\
Log likelihood & & & 8.0570 \\
Pseudo R2 & &
\end{tabular}

in our model are not equal to zero. It implies that our model as a whole fits significantly better than an empty model (i.e., a model with no predictors).

The coefficient for OPDIPD has a negative sign consistent with our a priori expectation, and statistically significant at the 5 percent level of significance.

A unit increase in the ratio of outpatient department visits to inpatient days would lead to a decrease in hospital expected inefficiency score by 0.0951 , holding all other variables in the model constant. The higher a hospital's OPDIPD, the lower the predicted inefficiency score.

The coefficient for Bed occupancy rate has a negative coefficient indicating that the lower the bed occupancy rate the higher the inefficiency score. A $1 \%$ decrease in bed occupancy rate increases the inefficiency score by 1.097405 all other factors remaining constant. The score coefficient is statistically significant at the $1 \%$ level $(p<0.01)$.

Our results indicate that hospital size is a significant factor in explaining hospital inefficiency. The results indicate that the predicted inefficiency score for big hospitals is 0.32 points lower than for small hospitals all other factors remaining constant. This suggests that small hospitals are less efficient than big hospitals. The results also indicate that the predicted inefficiency score for government hospitals is 0.919808 higher than that for PNFP hospitals all other factors remaining constant, suggesting that PNFP hospitals are more efficient than government hospitals. However the coefficient for this variable is not significant.

\section{Scope for output increases/input reductions to improve efficiency}

DEA calculates the efficiency score of a hospital of interest (target hospital) by comparing it with its efficient reference set. Thus, DEA outputs include an efficient reference set and corresponding weights (Refer to Table 4). Weighting of the efficiency reference set hospital inputs and outputs yields a hypothetical hospital (composite hospital) that produces as much or more than the target hospital but also uses fewer inputs. The difference between the inputs and outputs of the composite hospital and those of the target hospital indicates the input or output changes required to make the target hospital efficient.

Table 6 shows the input reductions and/or output increases that would have been required to make the individual pure technically inefficient hospitals efficient. To determine these, the inputs and outputs of a composite projected hospital are determined by multiplying the DEA- generated weights of each of the hospitals in the efficiency reference set used to identify an individual hospital's inefficiency with each reference hospital's actual outputs and inputs. The sum of the products of the multiplication is then compared to the inefficient hospital's outputs and inputs.

Naguru Hospital, for example, with a Technical efficiency score of 0.523887 (based on an efficiency reference set comprising Gulu with DEA generated weight of 0.408324; and Moroto with DEA generated weight of 0.077042 ) would need to increase its outpatient department visits by $45,943(130 \%)$ in order to become technically efficient while maintaining its current level of inputs. Alternatively, it could also become technically efficient by reducing its total medical staff by $73(48 \%)$ and its bed capacity by 48 beds ( $48 \%$ ) as well, while maintaining the current level of outputs. The required changes per hospital vary; ranging from a required increase in OPD visits between $0 \%$ and $130 \%$ with an average of $14 \%$. For patient days, the required increases range from 0 to $52 \%$ with an average of $7 \%$. For inputs, the required decreases for medical staff range from 3 to $48 \%$ with an average of $17 \%$ while for beds, the required decreases range from 2 to $48 \%$ with an average of $20 \%$.

\section{Discussion}

One approach to strengthening health services is through enhancing efficiency in utilization of existing resources to ensure that they are functioning to the best of their capacity with what is available so that the greatest health benefit possible may be attained. Improving efficiency is important at all levels, but the potential impact is particularly great in hospital services which use quite a substantial amount of health inputs. Measuring the efficiency of hospitals at the meso-level (e.g. regional) of the health system is useful for assessing and responding to variation in the performance of comparable hospitals. By directing attention to hospitals at the high and low extremes of efficiency, it is possible to gain insight into what 
Table 6 Efficiency scores and actual and target inputs and outputs quantities for inefficient hospitals according to VRS assumption

\begin{tabular}{|c|c|c|c|c|c|c|}
\hline Hospital & Score-VRS & Input/output & Actual quantity & Target quantity & Difference & Percentage \\
\hline \multirow[t]{4}{*}{ Arua } & 0.855481 & Medical Staff & 198 & 164 & -34 & $-17 \%$ \\
\hline & & Beds & 316 & 270 & -46 & $-15 \%$ \\
\hline & & OPD Visits & 176689 & 176689 & 0 & $0 \%$ \\
\hline & & Patient Days & 90231 & 90,231 & 0 & $0 \%$ \\
\hline \multirow[t]{4}{*}{ Fort Portal } & 0.921675 & Medical Staff & 189 & 174 & -15 & $-8 \%$ \\
\hline & & Beds & 371 & 300 & -71 & $-19 \%$ \\
\hline & & OPD Visits & 190665 & 190665 & 0 & $0 \%$ \\
\hline & & Patient Days & 88832 & 99260 & 10428 & $12 \%$ \\
\hline \multirow[t]{4}{*}{ Jinja } & 0.86767 & Medical Staff & 219 & 190 & -29 & $-13 \%$ \\
\hline & & Beds & 443 & 316 & -127 & $-29 \%$ \\
\hline & & OPD Visits & 160387 & 160387 & 0 & $0 \%$ \\
\hline & & Patient Days & 108007 & 108007 & 0 & $0 \%$ \\
\hline \multirow[t]{4}{*}{ Kabale } & 0.843276 & Medical Staff & 130 & 110 & -20 & $-15 \%$ \\
\hline & & Beds & 252 & 203 & -49 & $-19 \%$ \\
\hline & & OPD Visits & 138321 & 138,321 & 0 & $0 \%$ \\
\hline & & Patient Days & 70396 & 70,396 & 0 & $0 \%$ \\
\hline \multirow[t]{4}{*}{ Soroti } & 0.941373 & Medical Staff & 178 & 168 & -10 & $-6 \%$ \\
\hline & & Beds & 254 & 239 & -15 & $-6 \%$ \\
\hline & & OPD Visits & 121629 & 121629 & 0 & $0 \%$ \\
\hline & & Patient Days & 96558 & 96558 & 0 & $0 \%$ \\
\hline \multirow[t]{4}{*}{ Mubende } & 0.850297 & Medical Staff & 112 & 95 & -17 & $-15 \%$ \\
\hline & & Beds & 175 & 149 & -26 & $-15 \%$ \\
\hline & & OPD Visits & 86715 & 86715 & 0 & $0 \%$ \\
\hline & & Patient Days & 62456 & 62,456 & 0 & $0 \%$ \\
\hline \multirow[t]{4}{*}{ Naguru } & 0.523887 & Medical Staff & 153 & 80 & -73 & $-48 \%$ \\
\hline & & Beds & 100 & 52 & -48 & $-48 \%$ \\
\hline & & OPD Visits & 35390 & 81,333 & 45943 & $130 \%$ \\
\hline & & Patient Days & 24382 & 24382 & 0 & $0 \%$ \\
\hline \multirow[t]{4}{*}{ Rubaga } & 0.762422 & Medical Staff & 256 & 195 & -61 & $-24 \%$ \\
\hline & & Beds & 271 & 207 & -64 & $-24 \%$ \\
\hline & & OPD Visits & 155544 & 155544 & 0 & $0 \%$ \\
\hline & & Patient Days & 40380 & 61377 & 20997 & $52 \%$ \\
\hline \multirow[t]{4}{*}{ Mbarara } & 0.976592 & Medical Staff & 197 & 192 & -5 & $-3 \%$ \\
\hline & & Beds & 323 & 315 & -8 & $-2 \%$ \\
\hline & & OPD Visits & 155185 & 155,185 & 0 & $0 \%$ \\
\hline & & Patient Days & 116277 & 116277 & 0 & $0 \%$ \\
\hline
\end{tabular}

makes production processes work in their setting and focus supportive efforts where they are most needed.

This study provides two main perspectives on hospital efficiency in Uganda. Firstly, the study reveals variations in the efficiency of the regional referral and large PNFP hospitals studied. The constant return to scale technical efficiency score varied from a minimum of $43.1 \%$ and a maximum of $100 \%$; the pure technical efficiency score varied from a minimum of $52.4 \%$ and a maximum of
$100 \%$ while the scale efficiency score varied from a minimum of $43.1 \%$ to a maximum of $100 \%$. This indicates that despite facing similar resource-constrained conditions with similar inputs, some hospitals are more successful in converting inputs to outputs than others. The study identifies the following as determinants of hospital efficiency among the sampled hospitals: hospital size, bed occupancy rate and outpatient department visits as a proportion of inpatient days. 
Secondly the study determines the level of output increases or input reductions that were required to be made by the inefficient hospitals in order to become relatively efficient. These changes would translate into a 45,943 increase in outpatient department visits and 45,943 in-patient days without changing the total number of inputs. In other words, these are the potential gains that should be reaped by the health sector at no extra cost if these inefficient hospitals were to operate efficiently. Alternatively, efficiency would be achieved by reducing the total number of medical staff by 216 and reducing the total number of beds by 454 without changing the total number of outputs. One can argue that these are idle resources that can be re-deployed to other levels of the health system. In the current situation of existing unmet need and low quality of care, these efficiency savings can be invested to expand access and/or improve quality of care.

However, our study indicates that small hospitals are less efficient than large hospitals suggesting that redeploying apparently excess hospital beds (thus reducing hospital size) is likely to further reduce hospital efficiency. Additionally, given the level of unmet need in Uganda for a number of hospital services like surgery (43); the small number of health worker inputs per hospital as compared to established staffing norms and the decision-making responsibilities accorded to the hospital managers, our results should guide efforts to increase utilization rather than to evaluate resource allocation. This is supported by our study finding that increasing bed occupancy rate reduces hospital inefficiency.

The assessment of the efficiency of regional and large PNFP hospitals in Uganda as undertaken in this study provides an important complement to existing knowledge about performance of these hospitals and demonstrates use of routinely available data (through the HMIS) to contribute to improving efficiency of the various hospitals. The findings indicate hospitals at the high and low extremes of efficiency and the input and output changes required to make the hospitals more efficient. The findings can be useful to managers in directing their efforts and to gain further insight into factors that facilitate and inhibit production processes in various hospital contexts.

Application of DEA to assess hospital efficiency in Africa has increased in recent years. Our study contributes to a growing literature on efficiency analysis in Africa generally and specifically to an incipient literature on hospital efficiency in Uganda. The last published DEA study in Uganda reports an average technical efficiency score of $97.3 \%$ among the hospitals studied [28] which is higher than the average technical efficiency score of $91.4 \%$ obtained in our study. Similar studies in Uganda's regional peers Kenya [6] and Tanzania [44] found average technical efficiency scores of $95.6 \%$ and
$76.9 \%$ respectively. While it is not possible to compare the true efficiency of hospitals across settings because the technical efficiency scores are calculated in relation to the frontier of efficiency in each sample, it is noteworthy that the average technical efficiency score of $91.4 \%$ reported in our study is lower than that reported in Kenya but higher than that reported in the study in Tanzania. However, there were differences in the hospitals studied, with the Kenya study focusing on public hospital and the Tanzania study focusing on faith based hospitals (private not profit) while our study focused on both.

\section{Study limitations and suggestions for further research}

The study reported in this paper has a number of limitations and also raises some areas for further study.

A key limitation of the study is the small sample size involved. This is important since DEA produces results that are very sensitive to measurement error, especially in small samples. A small sample size may result in many hospitals becoming efficient by default (as a result of not having a comparator from within the small sample). To address this problem to some extent, we used the rule of thumb that the sample size should be at least three times the sum of number of inputs and outputs. Also, the study included 17 out of the 18 (94\%) regional referral hospitals active during the study period. The sample size for a similar study in Eritrea [4] comprised 19 out of 20 hospitals (95\%) this number is not very much different from the sample size in our study.

Data envelopment analysis (DEA) the analysis technique used in this paper is deterministic; meaning that estimation of an error term is not involved. The absence of an error component means that any deviation from the production possibilities frontier is attributed to inefficiency; there is no allowance for consideration of "random noise" such as epidemics, natural disasters which are out of a hospital's direct control and yet may affect its performance. It may be interesting to conduct the same study using econometric techniques that take into consideration random errors (e.g. SFA) in order to validate the efficiency scores from this study. Use of both DEA and SFA has been recommended by Coelli and colleagues and implemented by Jacobs [45] and Linna [46].

Due to lack of data, the study did not include expenditure on pharmaceuticals and other non-pharmaceutical supplies among the inputs. Also, as one of the inputs the various categories of health workers (doctors, nurses, Clinical officers, Laboratory technicians and anesthetic officers) were all lumped together as medical staff due to absence of a detailed breakdown of staff categories for all the sampled hospitals. This may mask differences in the composition of the available health workers (e.g. doctors, nurses, lab technicians etc.) in the different hospitals considered. Additionally, even within the same 
health workforce category, the quality of labour input may vary depending on individual health worker skills, motivation and professional experience.

Estimation of allocative efficiency requires data on quantities of health service outputs, health system inputs, and input prices. Since we did not have the data on input prices, we focused only on the technical efficiency and scale efficiency of the hospitals in our study.

The hospitals included in the study were all referral hospitals. It is however possible that there were differences in the severity of cases treated in each hospital. This data was not available since the study relied on secondary data. Significant differences in the severity of cases treated could affect the number of cases hospitals dealt with relative to their staff numbers and bed numbers and could therefore have an impact on the results of the analysis. The hospitals treating a large number of severe cases, for example, may handle fewer cases, and will thus appear to be relatively inefficient. Adjusting for case-mix in the analysis would have helped address this problem and also provide better justification for the input variable reductions or output increases proposed for the hospitals identified by this study as being inefficient.

Whereas the data used for the study is relatively recent, some of the highlighted limitations above mean that the results of this analysis cannot be uncritically fed into current decision making. The study however illustrates the potential usefulness of efficiency analyses as conducted in this study using routinely available data. These analyses would be made useful if they are used to measure trends in efficiency and productivity of hospitals over time $[6,8,17,33]$ for example using Malmquist Total Factor Productivity Index analysis. This a potential area for further research that would entail collecting inputs and outputs data for a number of years and would permit tracking and comparison of hospital efficiency over time.

\section{Conclusion}

In order to improve hospital performance, health policy makers need information about how well the hospitals are utilizing the resources they receive. This study has shown how DEA methods can be applied at the mesolevel (regional) of the health system to gain insight into variation in efficiency across hospitals using routinely available data. The findings provided empirical evidence of the technical efficiency of the sampled hospitals and the input and output changes required to make the inefficient hospitals relatively efficient. The study also identifies hospital size (SIZE), bed occupancy rate (BOR) and outpatient visits as a proportion of inpatient days (OPDIPD) as the main driver of efficiency among hospitals. Further work is however required to support hospital managers in putting the results to use in enhancing efficiency. Hospitals identified at the high and low extremes of efficiency should be investigated further to determine how and why production processes are operating differently at these hospitals.

Given the small number of health worker inputs per hospital as compared to established staffing norms and limited control of hospital managers over inputs at the hospital level as well as the degree of unmet need for hospital services in Uganda, efforts to enhance efficiency should focus on strategies to increase demand and utilization of services (outputs) rather than reduction of inputs. As policy makers gain insight into mechanisms promoting hospital services utilization in hospitals with high efficiency, such as engagement with community leaders and improving quality of care, they can develop context-appropriate strategies for supporting hospitals with low efficiency to improve their service and thereby better address unmet needs for hospital services in Uganda.

\section{Abbreviations \\ CRS, constant returns to scale; DEA, data envelopment analysis; DMU, decision making unit; FY, financial year; HSSIP, health sector strategy and investment plan (HSSIP 2010/11-; MOH, Ministry of Health; NGO, Non- Governmental Organization; OPD, Out Patient Department; PNFP, private not for profit; SUOS, standard units of output; VRS, variable returns to scale}

\section{Acknowledgements}

None.

\section{Authors' contributions}

PNM was overall in charge of designing the study, data collection, analysis, drafting the first version of the article and finalization of the article. EZA provided critical review, in-puts comments and revisions on the article throughout its course. JPP provided guidance for the study and in-puts and comments on the article throughout its course. All authors read and approved the final manuscript.

\section{Competing interests}

The authors declare that they have no competing interests.

\section{Author details}

'Department of Health Studies, Health Economist; Doctoral student, University of South Africa, College of Human Sciences, 1 Preller Street, Muckleneuk, Pretoria 0002, South Africa. ${ }^{2}$ Division of Health System Financing, Health Authority, Abu Dhabi, United Arab Emirates. ${ }^{3}$ Department of Economics and Business; and Centre for Research in Health and Economics (CRES), Universitat Pompeu Fabra, Ramón Trias Fargas 25-27, 08005 Barcelona, Spain.

Received: 30 November 2015 Accepted: 24 June 2016 Published online: 08 July 2016

\footnotetext{
References

1. WHO AFRO. Health financing: A strategy for the African Region. Brazzaville: WHO; 2006

2. Kirigia JM, Emrouznejad A, Cassoma B, Asbu EZ, Barry S. A performance assessment method for hospitals: the case of Municipal Hospitals in Angola. J Med Syst. 2008:32:509-19.

3. Zere E, Mbeeli T, Shangula K, Mandlhate C, Mutirua K, Tjivambi B, Kapenambili W. Technical efficiency of district hospitals: evidence from Namibia using data envelopment analysis. Cost Eff Resour Alloc. 2006;4:5.

4. Tlotlego N, Nonvignon J, Sambo LG, Asbu EZ, Kirigia JM. Assessment of productivity of hospitals in Botswana: a DEA application. Int Arch Med. 2010;3:1-14
} 
5. Masiye F. Investigating health system performance: an application of data envelopment analysis to Zambian hospitals. BMC Health Serv Res. 2007;7:58.

6. Kirigia JM, Emrouznejad A, Sambo LG. Measurement of technical efficiency of public hospitals in Kenya: using Data Envelopment Analysis. J Med Syst. 2002;26:39-45

7. Zere E, Mcintyre D, Addison T. Hospital efficiency and productivity inmthree provinces of South Africa. South Afr J Econ. 2005;69:336-58.

8. Kirigia JM, Sambo LG, Scheel H. Technical efficiency of public clinics in Kwazulu-Natal Province of South Africa. East Afr Med J. 2001;78(3 Suppl):S1-S13.

9. World Health Organization. The world health report: health systems financing: the path to universal coverage. Geneva: WHO; 2010.

10. Government of Uganda. National Health Accounts FY 2008/09 and FY 2009/10. Kampala: Ministry of Health;; 2013.

11. Government of Uganda. National Health Accounts: Key Messages (FY 2010/11-2011/12). Kampala: Planning Department, Ministry of Health; 2015.

12. National Health \& Hospitals Reform Commission. The Australian health care system: the potential for efficiency gains - A review of the literature. 2009.

13. Government of Uganda. National Housing and Population Census. Kampala: Uganda Bureau of Statistics (UBOS); 2014.

14. Government of Uganda. Health sector strategic and investment planPromoting people's health to enhance socio-economic development 2010/11-2014/15. Kampala: Ministry of Health; 2010.

15. Government of Uganda. National Hospital policy. Kampala: Ministry of Health; 2004.

16. Governent of Uganda. National Health policy-Reducing Poverty through improving people's health. Kampala: Ministry of Health; 2009.

17. Yawe BL, Kavuma SN. Technical efficiency in the presence of desirable and undesirable outputs: a case study of selected district referral hospitals in Uganda. Health Policy Dev. 2008;6(1):37-53.

18. Yawe B. Hospital performance evaluation in Uganda: a super efficiency data envelope analysis model. Zambia Soc Sci J. 2010; 1(No.1): Article 6.

19. Coelli T, Prasada Rao DS, O'Donnell CJ, Battese GE. An Introduction to Efficiency and Productivity Analysis. 2nd ed. New York: Springer; 2005.

20. Kumbhakar CS, Lovell CAK.Stochastic Frontier Analysis. Cambridge; Cambridge University Press; 2000.

21. Skaggs NT. Carlson: Microeconomics. London: Blackwell Publishers; 1996.

22. Fried HO, Lovell CAK, Schmidt SS. The measurement of productive efficiency: techniques and applications. New York: Oxford University Press; 1993.

23. Coelli TJ, Rao DSP, O'Donnell CJ. Battese GE: An introduction to efficiency and productivity analysis. London: Springer; 2005. p. 35.

24. Salvatore D. Managerial economics: principles and worldwide applications. New York: Oxford University Press; 2008.

25. Cooper WW, Seiford LM, Zhu J. Data envelopment analysis: history, models and interpretations. In: Cooper WW, Seiford LM, Zhu J, editors. Handbook on Data Envelopment Analysis, vol. 1. New York: Springer; 2011. p. 1-40.

26. Kirigia JM, Emrouznejad A, Sambo LG, Munguti N, Liambila W. Using data envelopment analysis to measure the technical efficiency of public health centers in Kenya. J Med Syst. 2004;28(2):155-66.

27. Kirigia JM, Mensah OA, Mwikisa CN, Asbu EZ, Emrouznejad A, Makoudode P, Hounnankan A. Technical efficiency of zone hospitals in Benin. Afr Health Monit. 2010;12:30-9.

28. Marschall P, Flessa S. Assessing the efficiency of rural health centres inBurkina Faso: an application of Data Envelopment Analysis. J Public Health. 2009;17(2):87-95.

29. Sebastian MS, Lemma H. Efficiency of the health extension programme in Tigray, Ethiopia: a data envelopment analysis. BMC Int Health Hum Rights. 2010;10:16.

30. Akazili J, Adjuik M, Jehu-Appiah C, Zere E. Using data envelopment analysis to measure the extent of technical efficiency of public health centres in Ghana. BMC Int Health Hum Rights. 2008:8:11.

31. Osei D, George M, DAlmeida S, Kirigia JM, Mensah AO, Kainyu LH. Technical efficiency of public district hospitals and health centres in Ghana: a pilot study. Cost Eff Resour Alloc. 2005;3:9.

32. Jehu-Appiah C et al. Ownership and technical efficiency of hospitals: evidence from Ghana using data envelopment analysis. Cost Eff Resour Alloc. 2014;12:9.

33. Ichoku H, Fonta WM, Onwujekwe OE, Kirigia JM. Evaluating the technical efficiency of hospitals in South Eastern Nigeria. Eur J Bus Manag. 2011;3(2):24-37
34. Kirigia JM, Emrouznejad A, Vaz RG, Bastiene H, Padayachy J. A comparative assessment of performance and productivity of health centers in Seychelles. Int J Product Perform Manag. 2008;57(1):72-92.

35. Renner A, Kirigia JM, Zere AE, Barry SP, Kirigia DG, Kamara C, Muthuri HK. Technical efficiency of peripheral health units in Pujehun district of Sierra Leone: a DEA application. BMC Heal Serv Res. 2005;5:77.

36. Kirigia JM, Sambo LG, Renner A, Alemu W, Seasa S, Bah Y. Technical efficiency of primary health units in Kailahun and Kenema districts of Sierra Leone. Int Arch Med. 2011:4:15.

37. Kirigia JM, Lambo E, Sambo LG. Are public hospitals in Kwazulu-Natal province of South Africa Technically Efficient? Afr J Health Sci. 2000;7(3-4):25-32.

38. Kirigia JM, Asbu EZ. Technical and scale efficiency of public community hospitals in Eritrea: an exploratory study. Health Econ Rev. 2013;3:6.

39. Government of Uganda. Annual Health Sector Performance Report FY 2012/13. Kampala: Ministry of Health; 2013.

40. Rosko MD, Chilingerian JA, Zinn JS, Aaronson WE. The effects of ownership, operating environment, and strategic choices on nursing home efficiency. Med Care. 1995;33:1001-21.

41. Vladmanis V. Sensitivity analysis for DEA models: an empirical example using public vs NFP hospitals. J Public Econ. 1992;48:185-205.

42. Coelli TJ. A guide to DEAP Version 2.1: a data envelopment analysis computer programme. CEPA Working Paper No. 8/96. Armidale: University of New England; 1996.

43. Ozgediz D, Galukande M, Mabweijano J, et al. The neglect of the global surgical workforce: experience and evidence from Uganda. World I Surg. 2008;32(6):1208-15.

44. Kembo M. Bwana. Measuring Technical Efficiency of Faith Based Hospitals in Tanzania: An application of Data Envelopment Analysis (DEA) Research in Applied Economics ISSN 1948-5433 2015, Vol. 7, No. 1.

45. Jacobs R. Alternative methods to examine hospital efficiency: data envelopment analysis and stochastic frontier analysis. J Med Syst. 2001:28(5):411-22

46. Linna M. Measuring hospital cost efficiency with panel data models. Health Econ. 1998;7:415-27.

\section{Submit your next manuscript to BioMed Central and we will help you at every step:}

- We accept pre-submission inquiries

- Our selector tool helps you to find the most relevant journal

- We provide round the clock customer support

- Convenient online submission

- Thorough peer review

- Inclusion in PubMed and all major indexing services

- Maximum visibility for your research

Submit your manuscript at www.biomedcentral.com/submit 